\title{
THORAX
}

Editorials

\section{Children and smoking: the problem and the way forward}

Physicians and surgeons are well aware of the risks of smoking, though when they are dealing with individual patients it is often difficult to grasp the scale of the problem. Yet the 110000 deaths attributed to smoking every year in the United Kingdom account for four times as many deaths as are caused by all accidents, violence, and drugs put together; up to one in four regular smokers will die prematurely from diseases caused by the habit. We can advise our patients to stop smoking, and try to help them do so, but by then it is usually late in the smoker's disease process. To achieve any real progress in preventing smokers' diseases, the emphasis must be on the prevention of smoking - that is, lifelong non-smoking.

There are over 14 million active smokers in the UK, and most of them started while they were children ${ }^{1}$; yet only $2 \%$ of these are glad that they started smoking, and $75 \%$ wish they had never done so. ${ }^{2}$ Consumption of tobacco and the percentage of the adult population of the UK who smoke have fallen over the last 30 years, ${ }^{3}$ but $30 \%$ of the adult population still smoke. Although smoking levels have fallen generally in the more prosperous countries of Europe, Australasia, and North America, cigarette smoking continues to increase rapidly in eastern and southern Europe, Africa, Asia, and Latin America. Such changes forewarn of a pandemic of smokers' diseases, which the World Health Organisation expects to account for 8 million deaths annually by the year 2025 .

Of great concern therefore are the numbers of young people who smoke. In the UK the prevalence of smoking is increasing among women-32\% of $16-19$ year olds smoke, and $39 \%$ of $20-24$ year olds. Among men the prevalence is static among $16-19$ year olds $(28 \%)$, but increasing in 20-24 year olds (to $38 \%$ ). ${ }^{4}$ The Government's green paper The Health of the Nation ${ }^{5}$ highlights the need for a reduction in smoking, with the target of reducing the number of adult smokers, including those of 16-19, by about a third. If this is to be achieved, the more that is known about smoking in children the better; a quarter of our children are regular smokers before they are 16 , and $80 \%$ of these will remain smokers for the rest of their lives, if the present trends continue. It is easy for children to start smoking; most live to regret it.

\section{Risks of smoking for children}

PASSIVE SMOKING

From conception onwards children can be injured by smoking. There is a $30 \%$ increase in the perinatal mortality of babies of smoking mothers, and there may be an increased risk of childhood cancers in the first five years of life. ${ }^{6}$ It is not clear whether the finding of marginally lower cognitive ability among the children of mothers who smoked during pregnancy is the result of passive smoking or related more to social disadvantages. ${ }^{7}$ After birth children who grow up in smoke have a greater risk of cot death, have more chest infections and pneumonia in the first year or two of life, and are more likely to have chronic ear infections. The frequency of respiratory symptoms in later childhood is increased, together with small but measurable reductions in lung function. ${ }^{89}$

\section{ACTIVE SMOKING}

The risks of passive smoking in the womb or during childhood are dwarfed by the risks of becoming an active smoker as a child. The earlier people start to smoke the more likely they are to become regular smokers, and therefore the greater the risk of smokers' diseases in later life. ${ }^{10}$ Those who start smoking as children also tend to smoke more heavily than those who start as adults. ${ }^{11}$ Children can acquire the habit very quickly-there is evidence from serial studies of salivary cotinine concentrations in children starting to smoke that cotinine concentrations rise very quickly as smoking becomes a regular habit, reflecting the early development of inhalation and suggesting that the pharmacological effects of nicotine are an early reinforcement to smoking. ${ }^{12}$

\section{Prevalence of smoking in childhood}

In the UK inquiries of the Office of Population, Censuses and Surveys (OPCS) show that children start to experiment with cigarettes at an early age; in England about $13 \%$ have tried smoking before they leave primary school at 11 , and $70 \%$ by age of 16 . Among 15 year olds a quarter are regular smokers, smoking an average of 53 cigarettes every week. A further $10 \%$ of 15 year olds are occasional smokers, having an average of six cigarettes a week. ${ }^{11}$ Such OPCS surveys have been undertaken every two years since 1982, and show a relatively stable pattern of cigarette consumption among schoolchildren over this period, with slightly fewer boys and slightly more girls taking up smoking. Those boys who smoke, however, tend to do so more heavily than the girls.

\section{Why do children start smoking?}

The question of why children start smoking has never been fully addressed. The process of becoming a smoker has, however, been analysed. Stem et ll $^{14}$ proposed a model of the stages of acquisition of cigarette smoking in adolescence as follows: (1) precontemplation; (2) contemplation, in which nor-smokers begin to see possible benefits of smoking; (3) action, where experimentation starts; and (4) the maintenance of the smoking habit. Such a model does not, however, explain what triggers off the "contemplation" stage or, more importantly, the "action" stage. This process clearly can be influenced by family, peers, personality, and whatever element there is of reinforcement from the pharmacological effects of nicotine. McNeill ${ }^{15}$ presents data from a recent small scale study suggesting that, far from taking about two years to pass from experimentation to habit, as is often suggested, children seem to have their smoking reinforced at an early stage, with nicotine apparently playing an important part. 
Characteristics of children who are most likely to be smokers

\begin{tabular}{ll}
\hline Characteristic & $\begin{array}{l}\text { Reference numbers of studies } \\
\text { showing characteristic }\end{array}$ \\
\hline Smoking parents & $16,17,20$ \\
Smoking siblings & $16,17,18$ \\
Single parent & 16 \\
Being a girl & 16 \\
Dismissive of health risks & $16,17,18$ \\
Susceptible to peer pressure & 18,21 \\
Fed up with school & 17 \\
Opposite sex friends & 18 \\
Intend to leave school early & 16,17 \\
See self as future smoker & 16 \\
Drink alcohol & 19 \\
Go to discotheques & $17,19,20$ \\
Go to pop concerts & 19 \\
Like alternative music & 19 \\
Prefer aromatic foods & 19 \\
Don't like apples & 19 \\
Wash hair more often & 17 \\
Play less active sports & 17 \\
Read fewer books & 17 \\
Brush teeth less often & 17
\end{tabular}

Inhalation is soon apparent in novice smokers, and most child smokers see themselves as having become dependent very quickly. Even the first few cigarettes are important in establishing dependence on smoking.

Many studies have aimed to characterise the background of young people who have started to smoke (table). Few studies, however, have attempted to explore why these sociodemographic, cultural, and attitude attributes are associated with a higher prevalence of smoking.

Hill $^{22}$ located 19 recently published reports of longitudinal studies on the uptake of smoking among schoolchildren. These studies were mainly conducted in the United States, although some British, Australian, and West German studies were also included. Many similar characteristics of "likely smokers" emerged, smoking by members of the family or peers and anti-school attitudes being important in almost all of the studies. Of course, the associations investigated were limited to those asked by the researchers, and may not represent the only factors.

The influences of the smoking behaviour of the mother, father, siblings, and other people in the family differ. Several studies indicate that the smoking behaviour of the mother has a stronger influence than the father's on the likelihood of smoking by the children. The influence of siblings is probably age related; those with older brothers and sisters (who by reason of age alone are more likely to be smokers themselves) are more likely to start smoking than those who have only younger, non-smoking siblings.

Outside the home other influences are also importantfor instance, the acceptability or otherwise of smoking in the community at large, in public places, and at school, and whether smoking or non-smoking the norm. We heard of an English primary school where not only was the smoke filled staff room easily visible to children but a teacher encouraged the use of empty cigarette packets for making models in a cardboard house.

The importance of advertising in encouraging smoking cannot be underestimated; this has been disputed by the tobacco industry and its advertisers, but there is sound evidence that children not only see advertising but absorb its messages. ${ }^{23}$ Cartoon characters ("Old Joe Camel") have been used in the United States both in Camel tobacco advertising and in films that appeal particularly to young children; paid promotions for Marlboro brand images have also appeared in such films. Children's toys carry tobacco logos. In addition to advertisements in newspapers and magazines and on billboards, children are exposed to large areas of advertising on shopfronts and to brand names in sports and other promotions. Tobacco advertising not only reinforces the habit among those children who already smoke but also encourages children to start smoking. ${ }^{24} 25$

The availability of cigarettes is another factor in making it easier for children to start smoking. For many years it has been illegal to sell cigarettes to children under 16, but most children have had no difficulty in buying cigarettes; indeed, only $15 \%$ of children in England were refused cigarettes the last time they tried to buy them. ${ }^{13}$

\section{How can potential smokers be identified?}

It is clear that future smokers have several characteristics, which may vary with gender, class, and family and home circumstances, and also with personality, personal tastes, and lifestyle. If tobacco use among young people is to be discouraged, it would be helpful to be able to identify and concentrate on those most likely to smoke.

Several authors have suggested characteristics that might be used to identify "likely smokers." Charlton and Blair ${ }^{19}$ studied a group of over 2300 children aged 12 and 13 by surveying attitudes initially and then observing the uptake of smoking in the subsequent four months. The attributes identified in those who became smokers were as follows: among girls, in declining order of importances, "having at least one parent who smokes"; "having positive beliefs about what smoking will do for you" (reduce weight, give more confidence, calm nerves); "having a best friend who smokes"; "knowing the name of at least one cigarette brand" and among boys, in declining order of importance, "having a best friend who smokes"; "knowing the name of at least one cigarette brand"; "having a favourite cigarette advert."

Others ${ }^{26}$ however, have questioned the strength of these data, suggesting that the "never smokers" in the initial survey may have included a group who had tried smoking but had not disclosed this, yet who were more likely to start smoking than the true never smokers. This group of undisclosed "triers" might contribute disproportionately to those taking up smoking in the short follow up period, the group whose characteristics were highlighted in Charlton and Blair's study.

Goddard $^{16}$ studied over 4000 children attending 32 secondary schools in England and Wales, surveying the same children for three consecutive years. She identified seven risk factors associated with starting to smoke: "being a girl"; "having brothers or sisters who smoke"; "having parents who smoke"; "living with a lone parent"; "having relatively less negative views about smoking"; "not intending to stay on in full time education after 16"; and "thinking that one might be a smoker in the future." All of these factors were associated independently with starting to smoke, though the magnitude of the independent effects was fairly small.

The conclusion of Charlton and Blair ${ }^{19}$ was that the order of their predicting factors was gender specific, but Goddard ${ }^{16}$ pointed out that, as girls were more likely to take up smoking than boys, "girls are at least an easily identifiable target group for health education-whereas those with particular attitudes are not."

In other studies further social characteristics have been identified. "Likely smokers" seem to adopt a lifestyle closer to that of adults, being socially precocious, but often having relatively low self esteem. They are more likely to be absent from school, to be poor achievers academically, and to have lower aspirations for future success. They may also have inadequate social skills and refusal skills, and are more likely to have behavioural difficulties. ${ }^{27}{ }^{28}$ Children who smoke are more rebellious than those who do not smoke. ${ }^{21}$ Ledwith $^{17}$ found that smokers were twice as likely to 
describe themselves as "fed up with school." Furthermore, Charlton and Blair ${ }^{19}$ found a higher level of smoking among children who were absent from school than in those who attended on a randomly chosen day, which confirms the less conformist behaviour among smoking schoolchildren. Finally, Goddard ${ }^{16}$ observed that "committed smokers of both sexes were more likely to see themselves as not conforming to expected behavioural norms." A further aspect of this is shown in a recent study, ${ }^{20} 39$ which found that particular types of music were more likely to be favoured by children who smoked, and at the time of the survey "house music," associated with more rebellious attitudes, and sixties music were more popular with smokers than non-smokers, whereas pop, charts and mainstream music were equally popular with all children. Such information may be helpful in "marketing" to specific target groups, for concentrating on certain groups who are most likely to "buy the product." For the purposes of antismoking campaigns, after the lifestyle patterns of the children most at risk of smoking have been identified it should be possible to target those children accordingly.

\section{How can children be helped to be non-smokers? PUBLIC ATTITUDES}

Tobacco smoking had become widespread among both sexes by the 1940s and 1950s, and achieved wide public acceptance in all social classes. It was only 30 years ago that the health risks of smoking began to be fully appreciated and widely published, after the first Royal College of Physicians Report. ${ }^{29}$ The uptake of smoking among children depends much on the attitude of society as a whole to tobacco, and if progress on smoking prevention among children is to be made it must be supported by changing attitudes among adults. A successful approach to smoking reduction in society will have to be comprehensive, involving people of all ages, and efforts will be effective only if there is encouragement from a well informed, consenting population. Such a programme is unlikely to succeed unless supported by appropriate legislation, fiscal policy, and continuing evaluation and research. We cannot expect children to stop smoking just because smoking adults tell them to do so, when adults themselves set an example of smoking at home and in public places.

\section{HEALTH EDUCATION IN SCHOOLS}

Many programmes of health education have been developed over the years, either purely on the smoking issue or as part of a more general programme. ${ }^{30}$ For instance, the Health Education Authority's project entitled My Body, a two year course aimed at 10-12 year olds, has been shown to reduce the uptake of smoking, and incidentally to decrease parental smoking. Important though this approach is in strengthening the beliefs of the children who are not smoking, it may not reach the children most likely to start smoking; we know that they are those who are unimpressed by health messages, and who are most at loggerheads with the school's authority. The problem is therefore unlikely to be solved by more school health education of the sort that concentrates on lectures about the health risks of smoking to the accompaniment of images of death and disease. Listening to children's views on smoking reveals that they are concerned about clean air and the environment, and that they worry about the health of family members who smoke. The "politics" of tobacco, tobacco advertising, and tobacco growing and promotion in developing countries are all areas where children can appreciate the impact of tobacco in a more immediate way than through the seemingly remote effects on their own health. Discussing these issues, and listening to what children think and believe about tobacco, may be a more productive approach in schools to help them to avoid becoming smokers. ${ }^{31}$

\section{SMOKEBUSTERS CLUBS}

Clubs for young non-smokers had their origin in Manchester as part of the "Smoke Free Project," and there are now 23 such clubs (active or about to start) in the UK, with other clubs as far afield as Australia and Portugal. The first such club to be fully evaluated started in Grampian, Scotland in $1987 . .^{32}$ It sought to recruit children to a club for non-smokers, aiming at the 10-13 year old age group (before most had started smoking), to make them feel good about being non-smokers-to see themselves as the strong ones, able to say "no" to cigarettes. Membership brought newsletters, stickers, activities, competitions, and a membership card, which acted as a discount card at nearly 200 shops and sports centres in the area, willingly supported by retailers and local authorities. The local media provided continuing encouragement and publicity. Children joined in large numbers, with $60 \%$ of the target group joining in the first year despite a $£ 1$ membership fee. The evaluation, so far reported after only 22 months of operation of the club, ${ }^{2033}$ showed an almost total awareness of the club among the target age group, and children in the area were smoking less than elsewhere in Scotland: those who joined the club were half as likely to start smoking in the next 22 months as those who did not join. Maybe these children were the conformist children who would not have smoked anyway. As the aim of the club was to achieve a long term reduction in the prevalence of smoking, a four year follow up evaluation is in progress. Although the long term success of such clubs in preventing (or delaying) the onset of smoking is sub judice, they do offer an alternative approach, giving children a non-smoking peer group for support, and providing them with ways of refusing cigarettes without loss of face- "I tried them but they didn't do anything for me"; "I gave them up ages ago!"; "I don't need them-I'm saving up for something special," to give some examples. As time has passed, the members of Smokebusters Clubs have become active in demanding smoke free zones and the abolition of tobacco advertising. Smokebusters Clubs, being seen as organisations detached from the schools (but operating with their help and support), can appeal to the more rebellious instincts of children in a more positive way; members see themselves as the strong ones who have resisted the unprincipled enticements of the tobacco industry, and anxious to prevent others from falling into the tobacco trap.

\section{SMOKING CESSATION FOR CHILDREN}

Many smoking children would like help in trying to stop smoking, and "stop smoking" clinics and programmes for children have been established and evaluated. ${ }^{27}$ Important though these initiatives are, prevention seems a more positive approach.

\section{PROHIBITION OF TOBACCO ADVERTISING}

It is astonishing that a product capable of causing lethal disease in a quarter of its users can still be advertised. The arguments in favour of an advertising ban are incontestable on ethical grounds, and are strongly supported by the British Thoracic Society and Doctors for Tobacco Law, but not yet supported by Government, which has favoured "voluntary agreements" with the tobacco industry to limit promotion. Not only does such an advertising ban seem ethically right, but there is mounting evidence from countries that include Norway, New Zealand, and Canada that advertising bans and curtailment of sponsorship of sports and the arts and of other forms of tobacco promotion 
are effective in reducing the numbers of young people recruited to smoking. ${ }^{34}{ }^{35}$ There is now evidence, from national opinion polls in the European Community, that $74 \%$ of European adults are in favour of an advertising ban. ${ }^{36}$

\section{REDUCED ACCESS TO CIGARETTES}

The recently passed Children and Young Persons (Protection from Tobacco) Act should help to make tobacco much less accessible to children by increasing the penalties for illegal sales, prohibiting sales of single cigarettes, and restricting access to vending machines.

\section{The future, and how doctors can help}

Success in the battle to reduce the disease and death caused by smoking will depend on public opinion, supported by political action. Most adults now accept that smoking is harmful, though the risks of passive smoking are not yet fully accepted. Political action in support will include the abolition of tobacco advertising and promotion in all its forms, the prevention of passive smoking by the prohibition of smoking in public places, and a progressive fiscal policy to deter smoking by increasing taxation. Such a programme sounds harsh and unsympathetic to those whose tobacco habit amounts to an addiction, and compulsive smokers need understanding and help. But a vital part of any smoking reduction programme is the prevention of smoking among children, with the aim of achieving a smoke free generation.

Doctors can make a major contribution in several ways, in particular because "the general public regards doctors as the best and most credible source of health information." Most clinicians are willing to set an example themselves by not smoking, though $10 \%$ of UK doctors still smoke. Members of the British Thoracic Society can (and should) support Doctors for Tobacco Law in its aim of eradicating tobacco promotion by political support of the European Community's initiative on tobacco promotion in Europe. The newly established journal Tobacco Control will provide a valuable focus for many workers in this area; we hope that it will not need to have a long era of publication. Doctors have many opportunities to raise the smoking and health issue in their contacts with patients and relatives, and to be prime movers in the full implementation of smoking policies in hospitals and public premises. On the specific issue of children and smoking, even those of us who do not treat children can give invaluable support to the local health promotion department and can encourage Smokebusters Clubs, or work for their establishment where they do not yet exist. The target of smoking prevention will need vigorous activity on a wide front over many years, and doctors have a special responsibility to lead the process.

\section{EDWIN VAN TEIJLINGEN}

Department of Sociology,

University of Aberdeen

JAMES A R FRIEND Department of Thoracic Medicine,
Aberdeen Teaching Hospitals

Reprint requests to: Dr J A R Friend, Chest Clinic, City Hospital, Aberdeen AB2 $1 \mathrm{NJ}$
1 Swan AV, Murray M, Jarrett L. Smoking behaviour from pre-adolescence to young adulthood. Aldershot: Avebury Press, 1991.

2 Consumers Association. No smoking please. Which? 1986:130-3.

3 Wald N, Nicolaides-Bouman A. UK smoking statistics. 2nd ed. Oxford: Oxford University Press, 1991.

4 General Household Survey. Cigarette smoking, 1972-1990. OPCS Monitor 1991:SS 91/3.

5 Secretary of State for Health. The health of the nation. London: HMSO 1991. (Cmnd 1523.)

6 Stjernfeldt M, Berglund K, Lindsten J, Ludvigsson J. Maternal smoking during pregnancy and risk of childhood cancer. Lancet 1986;i:1350-2.

7 Fergusson DM, Lloyd M. Smoking during pregnancy and its effects on child cognitive ability from the ages of 8 to 12. Paediatr Perinat Epidemiol 1991;5:189-200

8 Fielding JE, Phenow KJ. Health effects of involuntary smoking. $N$ Engl $J$ Med 1988;319:1452-60.

9 Charlton A. Children and passive smoking. 2nd ed. Edinburgh: Association of Non-smokers' Rights (Melgund Terrace, Edinburgh EH7 4BU), 1991.

10 Catford JC, Nutbeam D, Woolaway M. Effectiveness and cost benefits of smoking education. Community Education 1984;6:264-72.

11 Taioli E, Wynder EL. Effect of the age at which smoking begins on the frequency of smoking in adulthood. N Engl J Med 1991;325:968-9.

12 McNeill AD, Jarvis MJ, Stapleton JA, West RJ, Bryant A. Nicotine intake in young smokers: longitudinal study of saliva cotinine concentrations. $\mathrm{Am}$ Publ Health 1989;79:172-5.

13 Lader D, Matheson J. Smoking among secondary school children in 1990. London: HMSO, 1991.

14 Stem RA, Prochaska JO, Velicer WF, Elder JP. Stages of adolescent cigarette smoking acquisition: measurement and sample profiles. Addictive Behaviours 1987;3:319-29.

$15 \mathrm{McNeill} \mathrm{AD}$. The development of dependence on smoking in children. $\mathrm{Br}$ Addiction 1991;86:589-92.

16 Goddard E. Why children start smoking: an enquiry carried out by the social survey division of OPCS on behalf of the Department of Health. London: HMSO, 1990.

17 Ledwith F. A study of smoking in primary and secondary schools in Scotland. In: Fontana, F. Tobacco e giovani. (Conference Proceedings.) Padua: Lega Italia per la Lotto contro i Tumori, 1981:425-9.

18 Swan AV, Creeser R, Murray M. When and Why Children First Start to Smoke. Int J Epidemiol 1990;19:323-30.

19 Charlton A, Blair V. Predicting the onset of smoking in boys and girls. Social Science and Medicine 1989;29:813-8.

20 van Teijlingen E, Oldman IJ, Friend JAR. A short-term evaluation of Grampian smokebusters. Aberdeen: Department of Sociology, University of Aberdeen, 1990.

21 Aitken PP. Peer group pressure, parental control and cigarette smoking among 10 to 14 year olds. Br J Soc Clin Psychol 1980;19:141-6.

22 Hill D. Causes of smoking in children. In: Durston B, Jamrozik K, eds. Tobacco and health: the global war. (Proceedings of the Seventh World Conference on Tobacco and Health. Perth: Health Department of Western Australia, 1990:205-9.

23 Pierce JP, Gilpin E, Burns DM, Whalen MA, Rosbrook B, Shopland D, et al. Does tobacco advertising target young people to start smoking? JAMA 1991;266:3154-8.

24 Aitken PP, Eadie DR, Hastings GB, Haywood AJ. Predisposing effects of cigarette advertising on children's intentions to smoke when older. $B r$ Addiction 1991;86:383-90.

25 Hastings GB, Aitken PP, MacKintosh AM. From the billboard to the playground. London: Cancer Research Campaign, 1991.

26 Jarvis MJ, Goddard E, McNeill A. Do attitudes predict uptake of smoking in teenagers? Case not proven. Social Science and Medicine 1990;31: 997-1000.

27 International Union Against Cancer. A manual on tobacco and young people for the industrialised world. Geneva: UICC, 1990.

28 International Union Against Cancer. Children and tobacco: the wider view. Geneva: UICC, 1991 .

29 Royal College of Physicians. Smoking and health. London: Pitmans Medical, 1962.

30 Glynn TJ. Essential elements of school-based smoking prevention programs. Journal of School Health 1989;59:181-8.

31 Michell L. Growing up in smoke. London: Pluto Press, 1990.

32 Stevenson-Robb Y, Smokebusters. Journal of the Institute of Health Education 1989;27:193-6.

33 van Teijlingen E, Friend JAR. Smoking habits of Grampian schoolchildren and an evaluation of the Grampian Smokebusters campaign. Health Education Research (in press).

34 Action on Smoking and Health. Tobacco Advertising-the case for a ban. 3rd ed. London: ASH, 1991.

35 Coronary Prevention Group. The case against tobacco advertising. London: Coronary Prevention Group, (102 Gloucester Place, London W1H 3DA) 1991.

36 Adriaanse H, van Reek J. Adults in the European Community favour a tobacco advertising ban. Tobacco Control 1992;1:37.

37 Wallace PG, Haines AP, Brennan PJ. Are GPs doing enough to promote healthy lifestyle? $B M J$ 1987;294:940-2 